\title{
ENAMEL SURFACE QUALITY IMPROVEMENT IN WHITE SPOT LESIONS AFTER ORTHODONTIC TREATMENT USING A MICROABRASION TECHNIQUE WITH FLUORIDE OR CALCIUM PHOSPHOPEPTIDE-AMORPHOUS CALCIUM PHOSPHATE APPLICATION
}

\author{
NOVIRA MUTIA SAFITRI, HARU SETYO ANGGANI*, MIESJE KARMIATI PURWANEGARA, SARIESENDY SUMARDI
}

Department of Orthodontics, Faculty of Dentistry, Universitas Indonesia, Jakarta, Indonesia. Email: drg.vira@gmail.com

Received: 16 September 2017, Revised and Accepted: 3 October 2017

\section{ABSTRACT}

Objectives: White spot lesions after fixed orthodontic treatment will increase bacterial plaque formation due to increased enamel surface roughness. The aim of this study was to analyze the surface roughness of white spot lesions on enamel after a microabrasion technique, a microabrasion technique combined with calcium phosphopeptide-amorphous calcium phosphate (CPP-ACP) application, and a microabrasion technique combined with fluoride application.

Methods: Artificially induced white spot lesions on the enamel surfaces of 42 maxillary first premolars were randomly assigned into one of three treatment groups ( $\mathrm{n}=14$ ): (a) A microabrasion technique, (b) a microabrasion technique combined with CPP-ACP application, and (c) a microabrasion technique combined with fluoride application. A Mitutoyo SJ-301 surface roughness tester was used to measure differences in surface roughness before and after treatment, and the after treatment measurements were compared among the three groups.

Results: A significant difference in surface roughness was noted for the white spot lesions on enamel before and after treatment in all groups ( $\mathrm{p}<0.05$ ). A significant difference was also found when comparing the after treatment surface roughness in all groups.

Conclusion: The combination of the microabrasion technique with CPP-ACP application significantly reduced enamel surface roughness when compared to microabrasion alone or the combination of microabrasion and fluoride application.

Keywords: White spot lesion, Surface roughness, Microabrasion, Calcium phosphopeptide - amorphous calcium phosphate, Fluoride.

(c) 2017 The Authors. Published by Innovare Academic Sciences Pvt Ltd. This is an open access article under the CC BY license (http://creativecommons. org/licenses/by/4. 0/) DOI: http://dx.doi.org/10.22159/ijap.2017.v9s2.28

\section{INTRODUCTION}

One of the goals of orthodontic treatment is to improve the appearance of teeth and thereby the overall appearance of the patient. However, decalcification areas, also known as white spot lesions, sometimes form around the brackets and the bands during an orthodontic treatment [1]. A white spot lesion on tooth enamel is an unwanted risk that often occurs during fixed orthodontic treatments [2,3]. The prevalence of white spot lesions after these treatments varies between $2 \%$ and $96 \%$ [4]. Approximately $50 \%$ of patients treated with fixed appliances develop at least one white spot lesion [5], usually after 1 month of using the fixed orthodontic [6]. Mattousch et al. found that the white spot lesions appearing after completion of a fixed orthodontic treatment were irreversible unless specially treated. They reported that $40 \%$ of white spot lesions would improve without special treatment, $45 \%$ would remain the same, and $15 \%$ would worsen after 6 months of fixed orthodontic treatment [7].

Rough enamel surfaces facilitate the adhesion of bacteria and plaques, with the resulting formation of new white spot lesions. Plaque retention on the enamel surface also depends on the degree of surface roughness of the enamel: A rougher enamel surface will retain a higher number of bacteria. Hamdan et al. stated that $96 \%$ of the population, consisting of orthodontic patients, parents, orthodontists, and dentists, shared the opinion that the presence of white spot lesions after fixed orthodontic treatment reduced the esthetic appearance of teeth, even when the teeth were aligned [8]. Research by Parsons, who combined a microabrasion technique with calcium phosphopeptide (CPP)-amorphous calcium phosphate (ACP), indicated that this combination significantly reduced the depth of white spot lesions [9]. Enaia et al. found that removal of the remaining adhesive material with a bur or rotary instrument can cause demineralization of enamel crystals, increases in porosity, and permanent damage to the enamel surface of the tooth. This would lead to the increased roughness of the enamel surface and a greater risk of plaque accumulation [10].

Contemporary orthodontics is constantly updated with methods for improving the surface quality of tooth enamel. The choice of method can vary depending on the severity of the lesion. Several methods are available for treatment of white spot lesions, including microabrasion, fluoride application, and application of calcium phosphopeptideamorphous calcium phosphate (CPP- ACP) [11]. However, at present, the present authors have not found any study that reveals positive effects on for a combination of microabrasion and use of a remineralization agent, such as fluoride and CPP-ACP, as a treatment for white spot lesions or for minimizing enamel surface roughness.

The present research was conducted to analyze the effect of white spot lesion treatment after a fixed orthodontic treatment on the enamel surface roughness.

\section{METHODS}

This study was approved by the Ethical Committee Faculty of Dentistry, Universitas Indonesia. This was an analytical study with an experimental laboratory design. The study was conducted at the Dental Material Laboratory, Faculty of Dentistry, Universitas Indonesia. Samples were 42 maxillary first premolars.

The study focused on the buccal surface of the samples with the following inclusion criteria for the teeth: Extracted from orthodontic patients due to their treatment plan, not previously bonded, filling-free (e.g., amalgam and composite resin), no abnormalities (e.g., amelogenesis imperfecta, 
fluorosis, and dentinogenesis imperfecta), stain-free, white spot lesion-free, crack and caries free, and defect-free due to the extraction process.

The formation of artificial white spot lesion and the measurement of enamel surface roughness

The artificial white spot lesions on enamel were formed by soaking the buccal surface of each sample in $300 \mathrm{ml}$ of demineralization solution at $\mathrm{pH} 4$ at $37^{\circ} \mathrm{C}$ for $96 \mathrm{~h}$, rinsed with distilled water, and then dried with an air spray. The sample specimens were divided into three treatment groups: Group A underwent a microabrasion technique, Group B underwent the microabrasion technique as well as a CPPACP application, and Group C underwent a microabrasion technique combined with a fluoride application. The specimens were immersed using the $\mathrm{pH}$ cycle method: They were first soaked in demineralization solution $\left(20 \mathrm{ml}, \mathrm{pH} 4,37^{\circ} \mathrm{C}\right)$ for $6 \mathrm{~h}$, then soaked in artificial saliva solution $\left(20 \mathrm{ml}, \mathrm{pH} 7,37^{\circ} \mathrm{C}\right)$ for $18 \mathrm{~h}$; this cycle was repeated for 10 day. After 10 cycles, all specimens were removed from the artificial saliva solution, rinsed with water spray for $20 \mathrm{~s}$, and then dried with an air spray for $20 \mathrm{~s}$. All enamel surface roughness values were measured using the Mitutoyo SJ-301 surface roughness tester. The recorded test scores for the average surface roughness values were represented by the roughness average $(\mathrm{Ra})$ in units of micrometers $(\mu \mathrm{m})$.

\section{Statistical analysis}

Numerical data were analyzed using the Shapiro-Wilk normality test, Wilcoxon test, Kruskal-Wallis test, and post hoc Mann-Whitney test. Differences were considered statistically significant when $p<0.05$. All data were tabulated, and statistical tests were performed with the Special Package for the Social Sciences, version 17.0.

\section{RESULTS}

The results for the enamel surface roughness were not normally distributed and were analyzed using the Wilcoxon test (Table 1). The results for Group A showed a significantly smoother in the surface roughness values of the enamel white spot lesions after treatment. The results for Group B showed a significantly smoother in the surface roughness values of the enamel white spot lesions after treatment.

The results for Group C showed a significantly smoother in the surface roughness value of the enamel white spot lesions after treatment. The comparisons before and after treatment of the groups are shown in Table 2 .

The differences in surface roughness values for the enamel white spot lesions after treatment were analyzed using the Kruskal-Wallis and post hoc Mann-Whitney tests. Again, a significant difference was noted for the surface enamel roughness values after treatment among Groups A-C, indicating that the three methods had significantly different effects on reducing the surface roughness in the enamel of white spot lesions. The microabrasion technique combined with CPP-ACP application significantly reduced the enamel surface roughness when compared to microabrasion alone or microabrasion combined with fluoride application. The comparisons of the values after treatment in all groups are shown in Tables 3 and 4.

\section{DISCUSSION}

The presence of white spot lesions will affect the quality of the enamel because the lesions increase enamel roughness. The surface roughness of the enamel has been closely related to the adhesion ability of Streptococcus mutans bacteria on the surface of the enamel $[5,8,12]$. The attachment of $S$. mutans bacteria to the enamel surface was identified as one of the main factors in the formation of dental plaque, which is an early cause of white spot lesions that might progress into caries $[5,13]$.

During the treatments in the present study, the specimens were immersed using a $\mathrm{pH}$ cycle method based on the theory proposed by Ten Cate and Djuisetrs [4]. The $\mathrm{pH}$ of the artificial saliva was adjusted to $\mathrm{pH} 7$, while the $\mathrm{pH}$ of the demineralization solution was adjusted to $\mathrm{pH} 4$.
Table 1: Results of descriptive analysis (mean, SD, normality) of enamel surface roughness before and after treatment $(\mu \mathrm{m})$

\begin{tabular}{lllll}
\hline Groups & \multirow{2}{*}{} & \multicolumn{3}{l}{ Enamel surface roughness (Ra) } \\
\cline { 3 - 5 } & & & Mean \pm SD & p value \\
\hline $\mathrm{A}$ & \multirow{2}{*}{14} & $\mathrm{E}_{\text {before }}$ & $0.46 \pm 0.44$ & 0.022 \\
& & $\mathrm{E}_{\text {after }}$ & $0.33 \pm 0.03$ & 0.037 \\
$\mathrm{~B}$ & \multirow{2}{*}{14} & $\mathrm{E}_{\text {before }}$ & $0.44 \pm 0.03$ & $0.067^{*}$ \\
& \multirow{2}{*}{14} & $\mathrm{E}_{\text {after }}$ & $0.10 \pm 0.01$ & 0.000 \\
$\mathrm{~N}$ & $\mathrm{E}_{\text {before }}$ & $0.44 \pm 0.05$ & 0.046 \\
& & $\mathrm{E}_{\text {after }}$ & $0.19 \pm 0.04$ & $0.073^{*}$ \\
\hline
\end{tabular}

${ }^{*} \mathrm{p}>0.05=$ data normally distributed. Information: A group: A microabrasion technique, $B$ group: A microabrasion technique +CPP-ACP, $C$ group:

A microabrasion technique+fluoride

Table 2: Results of enamel surface roughness (Ra) before and after treatment $(\mu \mathrm{m})$

\begin{tabular}{|c|c|c|c|c|c|}
\hline \multirow[t]{2}{*}{ Groups } & \multirow[t]{2}{*}{$\mathbf{N}$} & \multicolumn{4}{|c|}{ Enamel surface roughness ( $R a)$ Wilcoxon test } \\
\hline & & & Median & Minimum-maximum & $\mathbf{p}$ \\
\hline \multirow[t]{2}{*}{ A } & \multirow[t]{2}{*}{14} & $\mathrm{E}_{\text {before }}$ & 0.46 & $0.40-0.52$ & \multirow[t]{2}{*}{$0.001^{*}$} \\
\hline & & $\mathrm{E}_{\text {after }}$ & 0.32 & $0.29-0.37$ & \\
\hline \multirow[t]{2}{*}{ B } & \multirow[t]{2}{*}{14} & $\mathrm{E}_{\text {before }}$ & 0.44 & $0.41-0.49$ & \multirow[t]{2}{*}{$0.001^{*}$} \\
\hline & & $\mathrm{E}_{\text {after }}$ & 0.10 & $0.10-0.11$ & \\
\hline \multirow[t]{2}{*}{$\mathrm{C}$} & \multirow[t]{2}{*}{14} & $\mathrm{E}_{\text {before }}$ & 0.43 & $0.40-0.50$ & \multirow[t]{2}{*}{$0.001^{*}$} \\
\hline & & $E_{\text {after }}$ & 0.18 & $0.17-0.22$ & \\
\hline
\end{tabular}

Information: ${ }^{*} \mathrm{p}<0.05=$ significantly different, A group: A microabrasion technique, B group: A microabrasion technique+CPP-ACP,

$\mathrm{C}$ group: A microabrasion technique+fluoride

Table 3: Results of enamel surface roughness (Ra) after treatment in three groups $(\mu \mathrm{m})$

\begin{tabular}{|c|c|c|c|c|c|}
\hline \multirow[t]{2}{*}{ Groups } & \multirow[t]{2}{*}{$\mathbf{N}$} & \multirow[t]{2}{*}{ Median } & \multicolumn{2}{|l|}{ Range } & \multirow{2}{*}{$\begin{array}{l}\text { Kruskal-Wallis } \\
\text { test } \\
\text { p }\end{array}$} \\
\hline & & & Minimum & Maximum & \\
\hline $\mathrm{A}$ & 14 & 0.13 & 0.04 & 0.17 & $0.000 *$ \\
\hline B & 14 & 0.33 & 0.30 & 0.38 & \\
\hline $\mathrm{C}$ & 14 & 0.23 & 0.19 & 0.33 & \\
\hline
\end{tabular}

Information: Kruskal-Wallis test, ${ }^{*} \mathrm{p}<0.05=$ significantly different, A group: A microabrasion technique, $B$ group: A microabrasion technique+CPP-ACP, C group: A microabrasion technique+fluoride

Table 4: Differences of enamel surface roughness (Ra) after treatment between two groups $(\mu \mathrm{m})$

\begin{tabular}{lll}
\hline Groups & Groups & $\begin{array}{l}\text { Post hoc Mann-Whitney test } \\
\mathbf{p}\end{array}$ \\
\hline A & B & $0.000^{*}$ \\
& C & \\
B & A & $0.000^{*}$ \\
& C & \\
C & A & $0.000^{*}$ \\
& B & \\
\hline
\end{tabular}

Information: ${ }^{*} \mathrm{p}<0.05=$ significantly different, A group: A microabrasion technique, $B$ group: A microabrasion technique +CPP-ACP, $C$ group: A microabrasion technique+fluoride

This $\mathrm{pH}$ cycle method is considered to represent the demineralization and remineralization processes that naturally occur in the oral cavity because acid $\mathrm{pH}$ occurs following $6 \mathrm{~h}$ of feeding and drinking activities by a patient and neutral $\mathrm{pH}$ occurs when the patient does not eat or drink [14].

White spot lesions may vanish following microabrasion due to the effects of erosion and abrasion of hydrochloric acid mixtures with silica applied 
with a low pressure micro motor. Etching with 11\% hydrochloric acid will create a hypermineralization layer in the white spot lesions so that the mechanical action of polishing with rubber cup easily lifts the white spot lesions. The purpose of polishing with a rubber cup is to activate the surface lesions and minimize healthy enamel retrieval. Therefore, one conclusion suggested by the present findings is that the use of a microabrasion technique can decrease the enamel surface roughness, but the result is not as smooth as when the microabrasion is combined with remineralization agents, such as CPP-ACP or fluoride [9].

A microabrasion treatment with CPP-ACP caused the greatest reduction in the enamel surface roughness when compared to the other two methods. CPP-ACP paste applied to the enamel surface in the oral cavity can bind 25 calcium ions, 15 phosphate ions, and 15 fluorine ions per molecule, and it can stabilize calcium phosphate in oral fluids. As a result, the $\mathrm{pH}$ of the oral cavity remains alkaline, which limits bacterial adhesion to the surface enamel, and it increases the process of remineralization and prevents the release of hydroxyapatite. The presence of phosphoryl residues may also sustain the amount of calcium phosphate ions in the oral cavity for a longer time than is possible with fluoride application. Reynolds stated that the CPP-ACP application enhanced the remineralization process to the subsurface of the enamel when compared to fluoride application [15]. This finding was reinforced by Ardu et al. [16], who reported that a microabrasion technique could eliminate the hypermineralization layer on the surface of enamel white spot lesions and could increase the porosity of the enamel surface by chemical and mechanical methods. The enamel porosity could increase CPP-ACP penetration into the subsurface of the enamel by reducing the depth of the white spot lesions and providing smoother enamel surfaces [16]. Pliska et al. suggested that a combination of a microabrasion technique with CPP-ACP could reduce the depth of white spot lesions, and they reported that the combined treatment gave better enamel color that was achieved with a microabrasion technique alone [17].

The present research showed that a microabrasion technique could reduce the surface roughness of the enamel, but the result was not as smooth as that achieved with an additional application of a remineralization agent such as fluoride or CPP-ACP. Treatment of enamel white spot lesions with fluoride could decrease surface roughness of white spot lesions up to the surface roughness value of enamel, which is considered as a critical boundary for bacterial adhesion. Hence, the Ra value of $0.20 \mu \mathrm{m}$ could indicate that the risk of bacterial adhesion after treatment of white spot lesions using a microabrasion technique was greater with fluoride application than with CPP-ACP application $[3,18]$.

This suggestion was consistent with the statement by Rogers et al. [3] that fluoride had the ability to withstand the demineralization process, due to the fluorapatite group bond formed on the surface of the enamel, but this bond was unable to bind calcium and phosphate ions to the surface of the enamel for a prolonged time [3]. Calcium and phosphate ions were necessary in the process of remineralization, but they were readily soluble in the oral saliva [3]. Therefore, fluoride application was incapable of improving subsurface enamel lesions to the extent possible with CPP-ACP [3]. Thus, the smoothness of the enamel surface after a microabrasion technique was not as smooth with fluoride application as it was with CPP-ACP application because fluoride could not repair the lesions in the subsurface enamel. Parsons also suggested that a microabrasion treatment could effectively reduce the depth of white spot lesions, but a remineralization agent was needed to obtain smooth enamel surfaces that were resistant to bacterial attack [9].

\section{CONCLUSION}

The plaque-forming bacteria in the oral environment can easily attach to rough enamel surfaces. This phenomenon emphasizes the importance of knowing which white spot lesion treatment method most effectively decreases the surface roughness of the enamel with white spot lesions.

The results of the present study show that the three methods of white spot lesion treatment (microabrasion alone, microabrasion combined with CPP-ACP, and microabrasion combined with fluoride) have the ability to cause a significant decrease in the roughness of the enamel surface. A microabrasion technique with CPP-ACP application gave a smoother enamel surface than was achieved with the other two methods, indicating that this combination is the most effective method for reducing the surface roughness of enamel with white spot lesions.

\section{ACKNOLEDGMENT}

The publication of this manuscript is supported by Universitas Indonesia.

\section{REFERENCES}

1. Faria-Júnior ÉM, Guiraldo RD, Berger SB, Correr AB, Correr-Sobrinho L, Contreras EF, et al. In-vivo evaluation of the surface roughness and morphology of enamel after bracket removal and polishing by different techniques. Am J Orthod Dentofacial Orthop 2015;147:324-9.

2. Behnan SM, Arruda AO, González-Cabezas C, Sohn W, Peters MC. In-vitro evaluation of various treatments to prevent demineralization next to orthodontic brackets. Am J Orthod Dentofacial Orthop 2010;138:712.

3. Rogers S, Chadwick B, Treasure E. Fluoride-containing orthodontic adhesives and decalcification in patients with fixed appliances: A systematic review. Am J Orthod Dentofacial Orthop 2010;138:390.

4. Bergstrand F, Twetman S. A review on prevention and treatment of postorthodontic white spot lesions-evidence-based methods and emerging technologies. Open Dent J 2011;5:158-62.

5. Srivastava K, Tikku T, Khanna R, Sachan K. Risk factors and management of white spot lesions in orthodontics. J Orthod Sci 2013:2:43-9.

6. Khalaf K. Factors affecting the formation, severity and location of white spot lesions during orthodontic treatment with fixed appliances. J Oral Maxillofac Res 2014;5:e4.

7. Mattousch TJ, van der Veen MH, Zentner A. Caries lesions after orthodontic treatment followed by quantitative light-induced fluorescence: A 2-year follow-up. Eur J Orthod 2007;29:294-8.

8. Hamdan AM, Maxfield BJ, Tüfekçi E, Shroff B, Lindauer SJ. Preventing and treating white-spot lesions associated with orthodontic treatment: A survey of general dentists and orthodontists. J Am Dent Assoc 2012;143:777-83.

9. Parsons T. In vitro Comparison of Microabrasion, CPP-ACP, CPP$\mathrm{ACPF}$ and Combination Therapies on the Remineralization of White Spot Lesions. Thesis: Nova Southeastern University; 2014. p. 1-16.

10. Enaia M, Bock N, Ruf S. White spot lesion during multibracket appliance treatment: A challenge for clinical excellence. Am J Orthod Dentofacial Orthop 2011;140:17-24.

11. Chambers C, Stewart S, Su B, Sandy J, Ireland A. Prevention and treatment of demineralisation during fixed appliance therapy: A review of current methods and future applications. Br Dent J 2013;215:505-11.

12. Joshi S, Joshi C. Management of enamel white spot lesions. J Contemp Dent 2013;3:133-7.

13. Chapman JA, Roberts WE, Eckert GJ, Kula KS, González-Cabezas C. Risk factors for incidence and severity of white spot lesions during treatment with fixed orthodontic appliances. Am J Orthod Dentofacial Orthop 2010;138:188-94.

14. ten Cate JM. Current concepts on the theories of the mechanism of action of fluoride. Acta Odontol Scand 1999;57:325-9.

15. Reynolds EC. Casein phosphopeptide-amorphous calcium phosphate: The scientific evidence. Adv Dent Res 2009;21:25-9.

16. Ardu S, Castioni NV, Benbachir N, Krejci I. Minimally invasive treatment of white spot enamel lesions. Quintessence Int 2007;38:633-6.

17. Pliska BT, Warner GA, Tantbirojn D, Larson BE. Treatment of white spot lesions with ACP paste and microabrasion. Angle Orthod 2012;82:765-9.

18. Bröchner A, Christensen S, Kristensen B, Tranaus S, Karlsson L, Sonnesen L, et al. Treatment of post-orthodontic with white spot lesions with casein phosphopeptide-stabilised amorphous calcium phosphate. Clin Oral Invest 2011;15:369-73. 